\title{
Graphene oxide modification for enhancing high- density polyethylene properties: a comparison between solvent reaction and melt mixing
}

https://doi.org/10.1515/polyeng-2018-0106

Received April 12, 2018; accepted July 25, 2018; previously published online August 28, 2018

Abstract: Graphene oxide (GO) was chemically modified in xylene with dodecyl amine and hydrazine monohydrate to obtain reduced functionalized graphene oxide (RFGO). Composites of high-density polyethylene (HDPE) and GO were made via solvent reaction, whereas both melt mixing and solvent reaction were used for HDPE-RFGO composites for comparison purposes. Elemental and thermal analysis showed the success of GO modification in grafting amine functionalities onto its structure and restoring most of the original graphene $\mathrm{C}=\mathrm{C}$ bonds. A significant increase in mechanical properties, thermal stability, and crystallization behavior was observed for HDPE-RFGO (solvent) compared with HDPE and HDPE-GO, proving that homogeneous dispersion of RFGO in the polymer matrix and strong interactions between them resulted in facilitated stress transfer, delayed thermal degradation, and more efficient nucleating effect in inducing the crystal growth of HDPE. A comparison of HDPE-RFGO properties enhancement between the melt mixing method and the solvent reaction method showed that, apart from mechanical behavior, the RFGO contribution was the same, suggesting that the optimization of the ecofriendlier approach (melt) could eventually lead to its total use for the mass production of high-performance, cost-effective, and more environmentally friendly graphene-based thermoplastic polyolefin nanocomposites suitable for highly demanding industrial applications.

Keywords: functionalization; graphene; nanocomposites; polyolefins.

\footnotetext{
*Corresponding author: Antimo Graziano, Center for Biocomposites and Biomaterials Processing, Faculty of Forestry, University of Toronto, Toronto, M5S 3BS, Canada, e-mail: antimo.graziano@mail.utoronto.ca. https://orcid.org/0000-0001-9846-9488
}

Shaffiq Jaffer: TOTAL American Services, Hopkinton, MA 01748, USA Mohini Sain: Center for Biocomposites and Biomaterials Processing, Faculty of Forestry, University of Toronto, Toronto, M5S 3BS, Canada

\section{Introduction}

Polyethylene (PE) is one of the most commonly used plastics in the world because of its high availability, low cost, and good properties [1]. Reinforcing it with a filler improves its properties, making it suitable for innovative and highly demanding applications [2-9]. Promising advances in nanofillers have made it possible to manufacture polymer nanocomposites with better properties, at a lower filler concentration because nanofillers have a very high surface area, leading to their homogeneous dispersion in the matrix [10-18]. Many studies have reported the improvement of high-density polyethylene (HDPE) properties when introducing carbon nano tubes (CNTs) as the reinforcement [19-23]. Nevertheless, the high manufacturing cost of CNTs has limited their mass production and their use in industrial applications [24]. Graphene is, in this case, gaining much interest because it can be made through alternative and cheaper manufacturing procedures, such as the modification of a cheap raw material: graphite [25-29]. Moreover, graphene is considered the strongest material in the world [30-36] and its planar structure leads to a more intimate contact with the polymer matrix, maximizing its properties. Few research studies on the reinforcement of HDPE with modified graphene have been carried out [37-39]. They have in common the oxidation of graphite to obtain graphene oxide (GO), followed by GO modification to produce reduced functionalized graphene oxide (RFGO), restoring the original structure of graphene and making it more compatible with HDPE. A great enhancement of thermal properties and crystallization behavior was reported when using the common approach of solvent reaction to create the HDPE-RFGO nanocomposites. However, this does not explain how GO is modified and the kind of chemical bonds that take place between HDPE and RFGO. Moreover, very little is understood about the effect of RFGO on the mechanical performance of HDPE. More importantly, the solvent reaction method tends to be neither ecofriendly nor cost-effective, although it ensures a very high level of intimate contact between polymer matrix and reinforcing agent. For this reason, mass 
production of HDPE-RFGO nanocomposites for advanced industrial applications cannot be fully encouraged yet. Very few studies have been done on making HDPE-RFGO via melt mixing $[40,41]$. Although a significant increase in mechanical performance, thermal stability, and crystallization behavior of HDPE-RFGO have been reported in these studies, they lack a comprehensive characterization of the GO modification procedure and its successfulness. Furthermore, none of the research studies mentioned previously compare the contributions in HDPE-RFGO properties enhancement brought by the solvent reaction method and the melt mixing method, leaving a gap in the understanding about the key differences between them when dealing with the manufacturing of high-performance and cost-effective graphene-based HDPE nanocomposites.

In this study, we use solvent reaction to make HDPERFGO, with the intent of better understanding the GO modification procedure and its effectiveness in restoring the graphene structure, as well as enhancing the affinity between HDPE and RFGO. Multiple characterization methods are used for assessing the successfulness of the GO modification method. Furthermore, a detailed (both qualitative and quantitative) analysis of the mechanical properties, thermal stability, and crystallization behavior of HDPE-RFGO has been reported to better evaluate the RFGO potential of increasing the HDPE performances. The melt blending method is also used and the improvement in HDPE properties is compared with the case of solvent reaction to investigate the possibility of switching from a complex, expensive, and non-environmentally friendly graphene-based polymer nanocomposites manufacturing method (solvent reaction) to a flexible, cheap, and ecofriendly one (melt mixing). Although the latter does not guarantee the same level of intimate contact between matrix and filler, the optimization of its effectiveness could lead to the same properties enhancement brought by solvent reaction, opening avenues for mass production of cost-effective and ecofriendly graphene-reinforced thermoplastic nanocomposites for tailored engineering applications.

\section{Materials and methods}

\subsection{Materials}

HDPE (BDM2-15/10) was supplied by Total SA, Houston, TX, USA. The melt flow index was $1.2 \mathrm{~g} / 10 \mathrm{~min}$, the density was $0.956 \mathrm{~g} / \mathrm{cm}^{3}$, and the melting point was $134^{\circ} \mathrm{C}$. GO powder, dodecyl amine (DA), hydrazine monohydrate, ethanol (EtOH), xylene, and acetone were purchased from Sigma Aldrich, Oakville, Ontario, Canada.

\subsection{Preparation of RFGO}

One gram of as-received GO was added to $100 \mathrm{ml}$ of distilled water and sonicated for $1 \mathrm{~h}$. Meanwhile, $3 \mathrm{~g}$ of DA was dissolved in $100 \mathrm{ml}$ of ethanol and then the suspension of GO and distilled water was added to make GO and DA react, at room temperature, for $24 \mathrm{~h}$, under vigorous stirring. Afterward, $10 \mathrm{ml}$ of hydrazine monohydrate was added and the reaction took place at $95^{\circ} \mathrm{C}$ for $4 \mathrm{~h}$ under vigorous stirring. The final product was filtered and washed with excess of distilled water and ethanol, then dried in a vacuum oven for $72 \mathrm{~h}$ at $60^{\circ} \mathrm{C}$. This produces the RFGO.

\subsection{Preparation of HDPE-RFGO composites via solvent reaction}

A total of $150 \mathrm{mg}$ of RFGO was added to $50 \mathrm{ml}$ of xylene and was sonicated for $1 \mathrm{~h}$, whereas $13.5 \mathrm{~g}$ of HDPE was dissolved in $250 \mathrm{ml}$ of xylene at $140^{\circ} \mathrm{C}$, under vigorous stirring, for approximately $30 \mathrm{~min}$, until a viscous solution of HDPE in xylene was obtained. At this point, the suspension of RFGO and xylene was added to make the reaction between HDPE and RFGO take place. The content was kept at $140^{\circ} \mathrm{C}$ for $20 \mathrm{~h}$, under vigorous stirring. The resulting material was filtered and washed with an excess of distilled water and acetone, then dried at room temperature for $48 \mathrm{~h}$, followed by vacuum drying at $75^{\circ} \mathrm{C}$ for $24 \mathrm{~h}$. The weight composition of RFGO in the composite was 1\%. HDPE-GO (99-1) composites were prepared, using the same method, for comparing their properties with the ones of HDPE-RFGO.

\subsection{Preparation of HDPE-RFGO composites via melt mixing}

Fifteen grams of HDPE-RFGO (99-1) composites were obtained via melt mixing in a laboratory mixing extruder (Dynisco, Franklin, MA, USA), having a rotor and barrel diameter of approximately 18.8 and $19 \mathrm{~mm}$, respectively. Its barrel length was $35 \mathrm{~mm}$. The rotor speed was $180 \mathrm{rpm}$ and the die temperature, as well as the barrel temperature, was $200^{\circ} \mathrm{C}$. The extrudate was then pelletized. 


\subsection{Characterization and testing}

\subsubsection{X-ray photoelectron spectroscopy}

Elemental analysis was done with a K-Alpha X-ray Photoelectron Spectrometer (Thermo Fisher Scientific, Waltham, MA, USA), using monochromated Al K-Alpha X-rays $(h v=1486.6 \mathrm{eV})$. Avantage software was used for curve fitting and calculation of atomic percentages.

\subsubsection{Thermal gravimetric analysis}

Thermal gravimetric analysis (TGA) was carried out using a thermal gravimetric analyzer, TA Instrument TGA Q500, Mississauga, Ontario, Canada, under nitrogen atmosphere. Approximately 5 to $8 \mathrm{mg}$ of as-obtained sample was subjected to a degradation process from room temperature to $600^{\circ} \mathrm{C}$, with a heating rate of $10^{\circ} \mathrm{C} / \mathrm{min}$.

\subsubsection{Tensile test}

Samples obtained via both solvent reaction and melt mixing were pressed in a hot press with plate temperatures of $190^{\circ} \mathrm{C}$. The amount of pressed material was roughly $7.5 \mathrm{~g}$ each time. The applied force was $2268 \mathrm{~kg}$ and the pressing time was $5 \mathrm{~min}$, followed by water cooling to room temperature at a rate of minus $50^{\circ} \mathrm{C} / \mathrm{min}$. The obtained sheets had an average thickness of $0.4 \mathrm{~mm}$. They were then cut into bone-shaped samples with a cross-sectional area of $3.18 \mathrm{~mm}$ (width) $\times 0.4 \mathrm{~mm}$ (thickness) and total length of $63.5 \mathrm{~mm}$, according to ASTM D638, sample type 5. Tensile tests were performed at ambient conditions using a universal testing equipment, Instron 3367 (Norwood, MA, USA). The cross-head speed was $3.175 \mathrm{~mm} / \mathrm{min}$, and the gauge length was $25.4 \mathrm{~mm}$. Six specimens were considered for testing.

\subsubsection{Heat deflection temperature}

Heat deflection temperature (HDT) was measured using a Q800 DMA analyzer (Instruments TA, USA). The three-point bending method was applied, with a heating rate of $2^{\circ} \mathrm{C} / \mathrm{min}$. The temperature range was room temperature to $60^{\circ} \mathrm{C}$. The average sample dimensions were $50 \mathrm{~mm}$ (length) $\times 5.5 \mathrm{~mm}$ (width) $\times 0.45 \mathrm{~mm}$ (thickness). The stress applied was $0.455 \mathrm{MPa}$, according to ASTM D648 requirements and the sample deflection as a function of temperature was registered. Two specimens were considered for testing.

\subsubsection{Differential scanning calorimetry}

Differential scanning calorimetry (DSC) was conducted using a DSC instrument (DSC Q1000, Mississauga, Ontario, Canada), under nitrogen atmosphere. Approximately 5 to $8 \mathrm{mg}$ of the as-obtained sample was first subjected to a cooling cycle, from $160^{\circ} \mathrm{C}$ to room temperature, at a rate of $10^{\circ} \mathrm{C} / \mathrm{min}$, to estimate its crystallization temperature $\left(T_{c}\right)$, and then to a heating cycle, from room temperature to $160^{\circ} \mathrm{C}$, at a rate of $10^{\circ} \mathrm{C} / \mathrm{min}$, to evaluate its melting point $\left(T_{\mathrm{m}}\right)$. The percentage of crystallinity $\left(X_{\mathrm{c}}\right)$ was calculated using the following equation:

$$
X_{\mathrm{c}}=\frac{\Delta H}{\Delta H_{0}} \times 100
$$

\subsubsection{X-ray diffractions}

X-ray patterns were registered using an X-ray diffractometer (Malvern, UK) PANalytical PW3710, using $\mathrm{CuK} \alpha$ radiation, with current intensity of $30 \mathrm{~mA}$ and generator voltage of $40 \mathrm{kV}$. Data were taken at a scan speed of 0.5 ${ }^{\circ} 2 \theta / \mathrm{min}$, step size of $0.02^{\circ} 2 \theta$, and at $2.5 \mathrm{~s}$ per step. The ${ }^{\circ} 2 \theta$ range considered was 5 to 30 . Hot-pressed samples were used for this analysis and they had a thickness of $0.4 \mathrm{~mm}$, a width of $15 \mathrm{~mm}$, and a length of $25 \mathrm{~mm}$.

\section{Results and discussion}

\subsection{Characterization of GO and RFGO}

Figure 1 illustrates the reaction processes involved in making HDPE-RFGO composites, starting from GO. First, the amine functionality is brought on the GO lattice through the solvent reaction with DA. Epoxy groups were broken to create covalent bonds between GO and DA. This is also called nucleophilic substitution from the amine functionality of DA to the epoxy functionality of GO. Moreover, during this process, the GO sheets are exfoliated by the presence of DA molecules, which are localized between adjacent GO layers [42]. The resulting product is functionalized graphene oxide (FGO). Although the new functional groups now allow strong interactions between polyethylene and FGO to take place, FGO has on its main structure many $s p^{3} \mathrm{C}-\mathrm{C}$ bonds. To recover the graphene properties, almost all the $s p^{2} \mathrm{C}=\mathrm{C}$ bonds need to be restored. Therefore, 


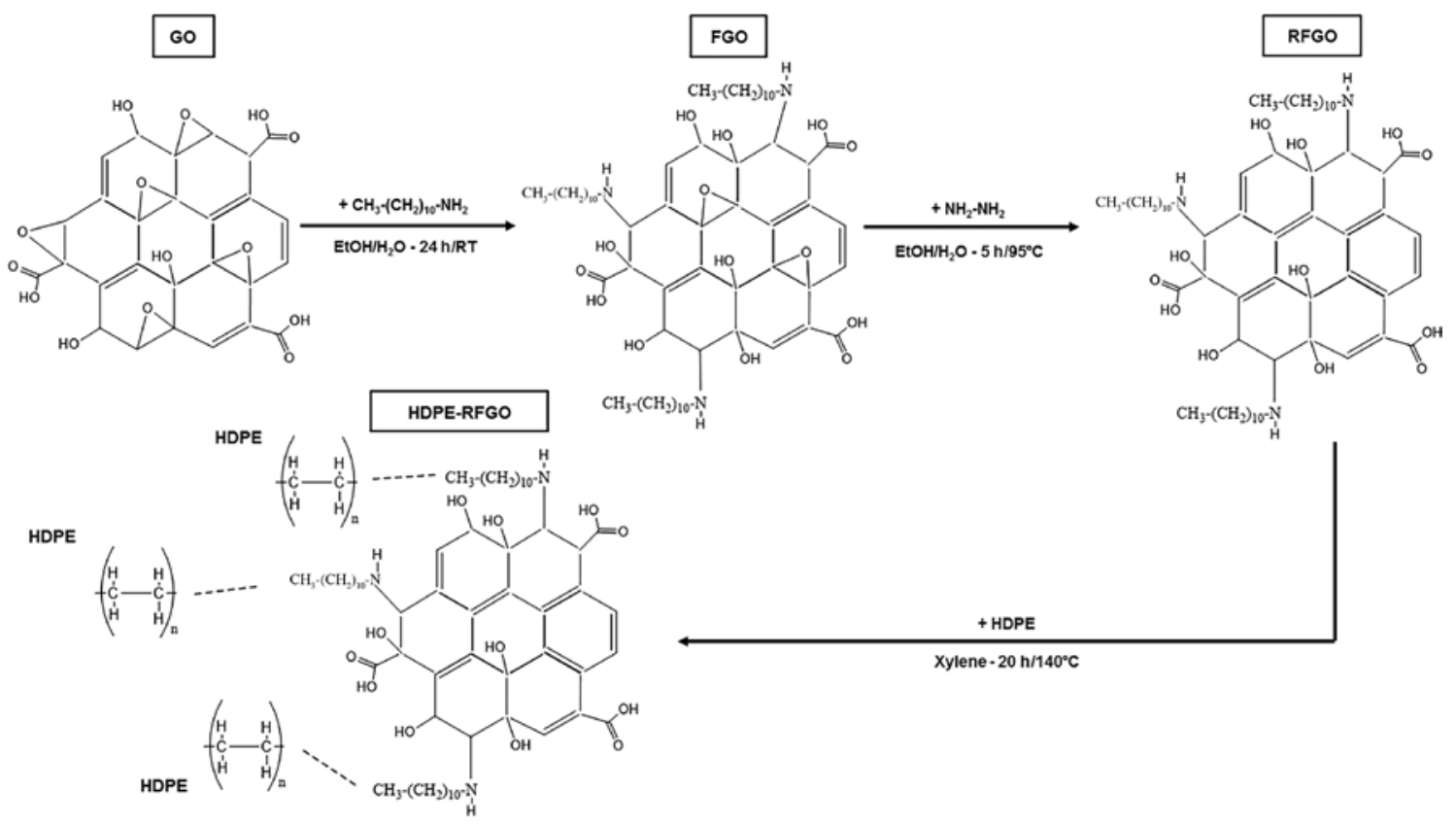

Figure 1: Scheme of the reactions used to make HDPE-RFGO composites from GO.

the following step consists of introducing hydrazine monohydrate to make it break more epoxy groups on the graphene lattice and restore most of the $\mathrm{C}=\mathrm{C}$ bonds. In this instance, the epoxy ring opens when introducing hydrazine monohydrate, and an initial derivative is produced on the epoxide opening, reacting further via the formation of an amino aziridine moiety. A double bond is then formed through thermal elimination, almost fully restoring the conjugated graphene structure [43]. This gives RFGO, which further reacts with polyethylene to make HDPE-RFGO, as shown in the last step of Figure 1. Bonding between polyethylene chains and DA molecules occurs via electron clouds or stacking interactions.

\subsection{Elemental analysis}

The chemical character of GO and RFGO surfaces was analyzed via X-ray photoelectron spectroscopy (XPS), and the whole wide scan spectrums are depicted in Figure 2. The C1s, O1s, and N1s peaks refer to the carbon, oxygen, and nitrogen bonds, respectively. When functionalizing and reducing $\mathrm{GO}$ to obtain $\mathrm{RFGO}$, the $\mathrm{C} 1$ s peak increases its intensity due to the breaking of epoxy groups on the GO lattice and the restoration of most of the $\mathrm{C}=\mathrm{C}$ bonds. Moreover, the amount of $\mathrm{C}-\mathrm{C}$ bonds is raised as well because alkyl groups were attached to GO when introducing DA [44]. Regarding the oxygen-related bonds, they are fewer in the case of RFGO compared with GO, as indicated by the reduced intensity of the 01s peak. Indeed, the reduction

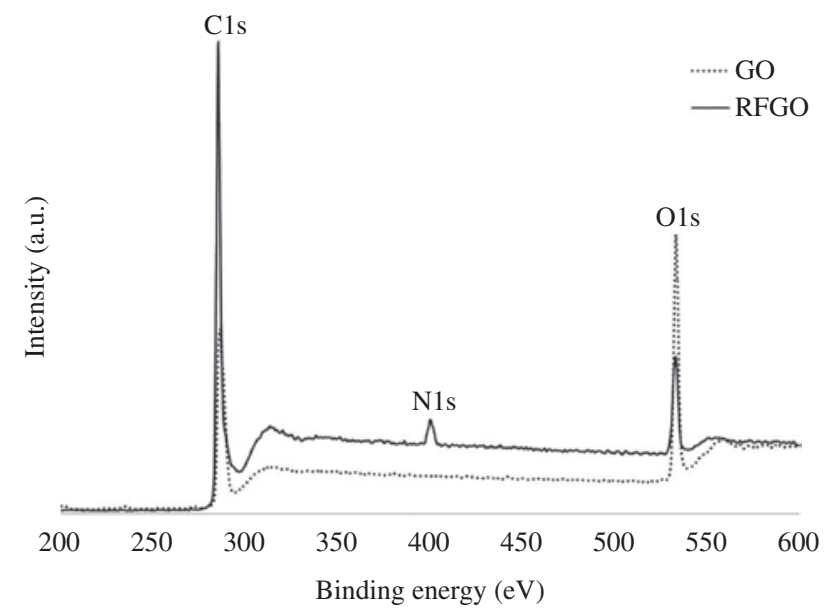

Figure 2: XPS wide scan spectrums of GO (dotted line) and RFGO (solid line).

process with hydrazine monohydrate lowers the amount of oxygen groups, by restoring most of the $\mathrm{C}=\mathrm{C}$ bonds. When looking at the N1s peak, this is present only in the case of RFGO, indicating that functionalization with DA and reduction with hydrazine monohydrate introduces $\mathrm{C}-\mathrm{N}$ and N-H linkages. This is another proof of the effectiveness of GO modification. When considering the whole XPS wide scan spectrum of a sample, the percentage of the total carbon-, oxygen-, and nitrogen-related linkages can be estimated from peak area and peak intensity of C1s, O1s, and N1s, respectively. The obtained values are depicted in Table 1. 
Table 1: Amounts of total carbon, oxygen, and nitrogen bonds for $\mathrm{GO}$ and RFGO.

\begin{tabular}{lrrr}
\hline & Tot C bonds (\%) & Tot O bonds (\%) & \multicolumn{1}{c}{ Tot N bonds (\%) } \\
\hline GO & 69.9 & 30.1 & - \\
RFGO & 83.3 & 11.8 & 4.9 \\
\hline
\end{tabular}

Table 2: Atomic composition and peak position of carbon bonds for $\mathrm{GO}$ and RFGO.

\begin{tabular}{|c|c|c|c|c|}
\hline & \multicolumn{2}{|r|}{ GO } & \multicolumn{2}{|r|}{ RFGO } \\
\hline & $\begin{array}{r}\text { Peak } \\
\text { position } \\
(\mathrm{eV})\end{array}$ & $\begin{array}{r}\text { Atomic } \\
\text { composition } \\
(\%)\end{array}$ & $\begin{array}{r}\text { Peak } \\
\text { position } \\
(\mathrm{eV})\end{array}$ & $\begin{array}{r}\text { Atomic } \\
\text { composition } \\
(\%)\end{array}$ \\
\hline$C=C$ & 284.1 & 29.4 & 284.3 & 35.3 \\
\hline$C-C$ & 284.4 & 35.7 & 285.1 & 38.7 \\
\hline C-O & 285.6 & 3.7 & 285.7 & 3.4 \\
\hline $\mathrm{C}-\mathrm{O}-\mathrm{C}$ & 286.5 & 28.3 & 286.8 & 1.3 \\
\hline $0-C=0$ & 288.3 & 2.9 & 289.3 & 2.1 \\
\hline C-N & - & - & 285.5 & 19.2 \\
\hline
\end{tabular}

Table 2 indicates the atomic composition and peak position (binding energy) of each carbon linkage for both GO and RFGO obtained from the convolution of their C1s spectrums, confirming the effectiveness of the modification procedure in increasing carbon bonds, reducing hydrogen linkages, and introducing nitrogen moieties to RFGO when going from GO to RFGO.

\subsection{Thermal stability}

Figure 3 represents the thermal degradation behavior of graphene, GO, and RFGO with increasing temperature to $600^{\circ} \mathrm{C}$, under nitrogen atmosphere. Graphene is made of

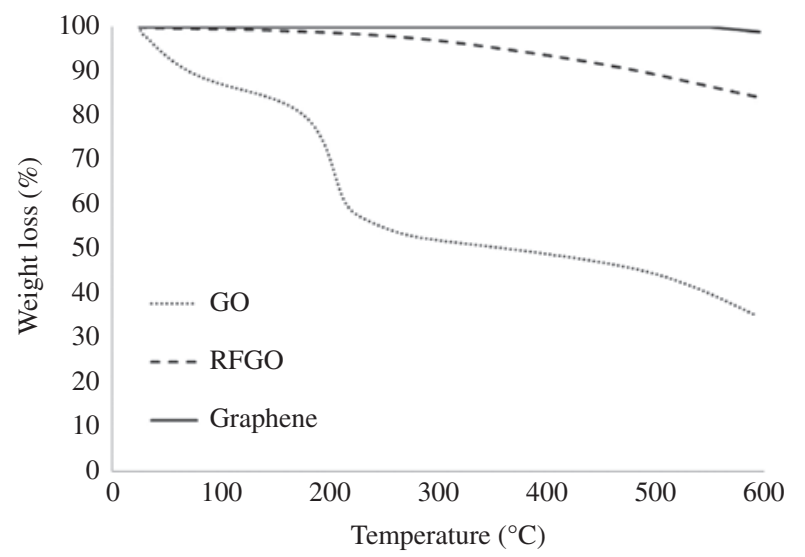

Figure 3: TGA curves of graphene (solid line), GO (dotted line), and RFGO (dashed line). only $s p^{2} \mathrm{C}=\mathrm{C}$ bonds so it does not degrade at that temperature. On the other hand, GO undergoes significant degradation, due to hydroxyl, epoxy, and carboxylic moieties [45]. When looking at the RFGO curve, it can be claimed that the reduction method was effective in at least partially restoring the graphene structure, because RFGO has a similar behavior as graphene, losing less than $20 \%$ of its weight. This indicates that the amount of oxygen-related functional groups is drastically reduced.

\subsection{Characterization of HDPE composites}

\subsubsection{Mechanical performance}

Table 3 depicts tensile strength, Young's modulus, and toughness of HDPE, HDPE-GO, HDPE-RFGO (melt) made via melt mixing, and HDPE-RFGO (solvent) made via solvent reaction. The filler concentration for all the composites is $1 \%$ wt. Compared with HDPE, all the properties of the composites increase in value, indicating that the filler enhances the polymer mechanical behavior. Moreover, RFGO contributes in a more powerful way than $\mathrm{GO}$, proving that RFGO is more homogeneously dispersed in the matrix and the interactions with the polymer are stronger, restraining the movement of HDPE chains. This results in increased strength and stiffness. Furthermore, the material absorbs a larger amount of energy before failure, upon deformation, indicating an increased toughness [46]. It can be thus claimed that GO modification was effective in increasing the RFGO degree of dispersion in HDPE to enhance the mechanical behavior of the polymer. Nevertheless, this is much more evident in the case of HDPE-RFGO (solvent) than the case of HDPE-RFGO (melt). Indeed, the enhancement of the mechanical properties for the composite made via melt mixing was minimal whereas the composite made via solvent reaction has a $25 \%$ increase in tensile strength, a 38\% increase in Young's modulus, and a $41 \%$ increase in toughness compared with HDPE. The specific interactions between HDPE and RFGO in the case of solvent reaction are much stronger than the

Table 3: Tensile strength, stiffness, and toughness of HDPE, HDPEGO, HDPE-RFGO (melt), and HDPE-RFGO (solvent).

\begin{tabular}{lrrr}
\hline & $\begin{array}{r}\text { Tensile } \\
\text { strength }(\mathbf{M P a})\end{array}$ & $\begin{array}{r}\text { Young's } \\
\text { modulus }(\mathrm{GPa})\end{array}$ & $\begin{array}{r}\text { Toughness } \\
\left(\mathbf{M J} / \mathbf{m}^{3}\right)\end{array}$ \\
\hline HDPE & 19.5 & 0.8 & 5.1 \\
HDPE-GO & 20.1 & 0.9 & 5.6 \\
HDPE-RFGO (melt) & 21.5 & 0.95 & 6.2 \\
HDPE-RFGO (solvent) & 24.3 & 1.1 & 7.2 \\
\hline
\end{tabular}


ones occurring during melt mixing because the mixing in the solution usually offers more intimate contact between the components [47].

Additionally, because we were dealing with a very short barrel length when using the laboratory mixing extruder apparatus, both sample residence time and amount of applied shear were not enough to ensure sufficient contact between the components for strong interactions to occur.

\subsubsection{Thermal stability}

As seen in the case of mechanical performance, the introduction of the filler to HDPE develops a more thermally stable material. Indeed, the onset degradation temperature (Td, 99\%), the temperature of maximum degradation (Td, max), the temperature at which $50 \%$ of the weight is lost ( $\mathrm{Td}, 50 \%$ ), and the temperature referring to $99 \%$ weight loss (Td, 1\%) increases when going from pure polymer to composite, as illustrated in Table 4.

This is because the reinforcement acts as a gas barrier and makes the polymer degrade at higher temperatures, increasing its thermal stability. Furthermore, this effect is more powerful when adding RFGO to HDPE, instead of $\mathrm{GO}$, proving the more effective interactions between HDPE and RFGO as well as the more homogeneous distribution of the latter in the former. Thermal degradation of polymers begins with $\mathrm{C}-\mathrm{C}$ scission into radicals and then into gas phase. Bubbles are first created around the heated area, then they burst and eventually create fuel vapor. Homogeneous distribution of RFGO in HDPE and strong interactions between them create a protective layer that delays the bubble growth rate, increasing the activation energy for thermal degradation, and hindering the diffusion of the decomposition products from the bulk polymer onto the gas phase [48]. Regardless of the manufacturing method used for making HDPE-RFGO composites (melt mixing or solvent reaction), the thermal stability is significantly increased, compared with pure polymer. Indeed, the thermal stability of the composite made via solvent reaction is only slightly higher than the one manufactured via melt mixing. This is because, even though the intimate contact and the specific interactions are not as strong in the case of melt mixing, RFGO still acts as an efficient gas barrier to delay the thermal degradation of the composite. Figure 4 qualitatively shows the contribution of $\mathrm{GO}$ and RFGO (in both the cases of melt mixing and solvent reaction) in increasing the thermal stability of HDPE.

\subsubsection{Crystallization behavior and HDT}

Table 5 depicts the melting temperature $\left(T_{\mathrm{m}}\right)$, crystallization temperature $\left(T_{c}\right)$, and degree of crystallinity $\left(X_{c}\right)$ for HDPE and the composites with GO and RFGO.

In general, the introduction of the graphene-based cofactor to the matrix increases all the properties mentioned above, showing a positive nucleating effect. Furthermore, when going from GO to RFGO, a more significant boost of $T_{\mathrm{m}}, T_{\mathrm{c}}$, and $X_{\mathrm{c}}$ is seen. This is because

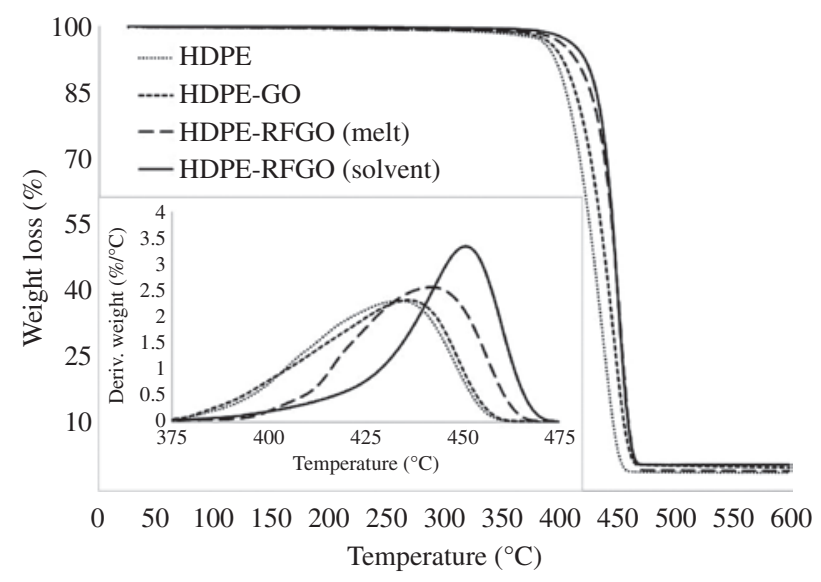

Figure 4: TGA curves of HDPE (round dotted line), HDPE-GO (square dotted line), HDPE-RFGO melt (dashed line) and HDPE-RFGO solvent (solid line). The derivative of the weight loss over temperature is represented in the insert of the figure.
Table 4: Degradation temperatures of HDPE, HDPE-GO, HDPE-RFGO (melt), and HDPE-RFGO (solvent).

\begin{tabular}{lrrrr}
\hline & $\begin{array}{r}\mathrm{Td}, \\
\mathbf{9 9 \%}\left({ }^{\circ} \mathrm{C}\right)\end{array}$ & $\begin{array}{r}\mathbf{T d}, \\
\mathbf{5 0}\left({ }^{\circ} \mathrm{C}\right)\end{array}$ & $\begin{array}{r}\mathrm{Td}, \\
\max \left({ }^{\circ} \mathrm{C}\right)\end{array}$ & $\begin{array}{r}\mathbf{T d}, \\
\mathbf{1 \%}\left({ }^{\circ} \mathrm{C}\right)\end{array}$ \\
\hline HDPE & 317.5 & 427.3 & 435.7 & 453.1 \\
HDPE-GO & 328.4 & 431.3 & 438.5 & 456.4 \\
HDPE-RFGO (melt) & 331.8 & 433.4 & 440.6 & 462.5 \\
HDPE-RFGO (solvent) & 333.1 & 433.6 & 442.8 & 463.9 \\
\hline
\end{tabular}

Table 5: Melting point, crystallization temperature, \% crystallinity, and HDT of HDPE, HDPE-GO, HDPE-RFGO (melt), and HDPE-RFGO (solvent).

\begin{tabular}{lccrr}
\hline & $\boldsymbol{T}_{\mathrm{m}}\left({ }^{\circ} \mathrm{C}\right)$ & $\boldsymbol{T}_{\mathrm{c}}\left({ }^{\circ} \mathrm{C}\right)$ & $\boldsymbol{X}_{\mathrm{c}}(\%)$ & HDT $\left({ }^{\circ} \mathrm{C}\right)$ \\
\hline HDPE & 133.3 & 118.8 & 63 & 47.1 \\
HDPE-GO & 134.1 & 119.8 & 67 & 48.2 \\
HDPE-RFGO (melt) & 134.2 & 121.2 & 70 & 51.4 \\
HDPE-RFGO (solvent) & 134.9 & 123.5 & 72 & 55.1 \\
\hline
\end{tabular}


RFGO is more homogeneously dispersed in HDPE and the interactions between them are stronger, improving the nucleating effect of RFGO. The HDPE crystals become bigger and thicker; therefore, $T_{\mathrm{m}}, T_{\mathrm{c}}$, and $X_{\mathrm{c}}$ increase. Heterogeneous crystallization is induced by RFGO twodimensional sheets, which create extra sites for crystal growth and facilitate nucleation by absorbing polymer molecules on its structure and decreasing the free energy of crystallization. Given the high aspect ratio and surface area of RFGO, along with its homogeneous dispersion in the matrix, a small amount of filler is sufficient for providing nucleation sites for improved polymer crystallization [49]. When comparing the two different manufacturing methods (melt mixing and solvent reaction), there is a significant increase in $T_{\mathrm{m}}, T_{\mathrm{c}}$, and $X_{\mathrm{c}}$ for HDPE-RFGO, in both cases, compared with HDPE. This is because, even though the contact between the components in the case of melt mixing is not as strong as the one when applying solvent reaction, the RFGO nucleating effect is still efficient in positively influencing the crystallization behavior of HDPE. The increase of nucleation sites due to the presence of RFGO in the polymer leads, in both cases, to a more facilitated HDPE crystal growth, with the formed lamellae having a higher thickness [50]. Another way to prove that the crystallinity of the polymer is enhanced by the introduction of the graphene-based cofactor is performing $\mathrm{X}$-ray diffraction (XRD) analysis. Figure 5 represents the XRD curves of HDPE and the composites prepared using the two different methods.

The intensities of the peaks refer to the crystallinity of the sample. The first peak at $2 \theta=21.5^{\circ}$ and the second one at $2 \theta=24^{\circ}$ relate to the (110) and (200) lattice planes of polyethylene in the composite, respectively. The peaks of HDPE-GO and HDPE-RFGO have higher intensities than the ones of HDPE, proving that the crystallinity increases

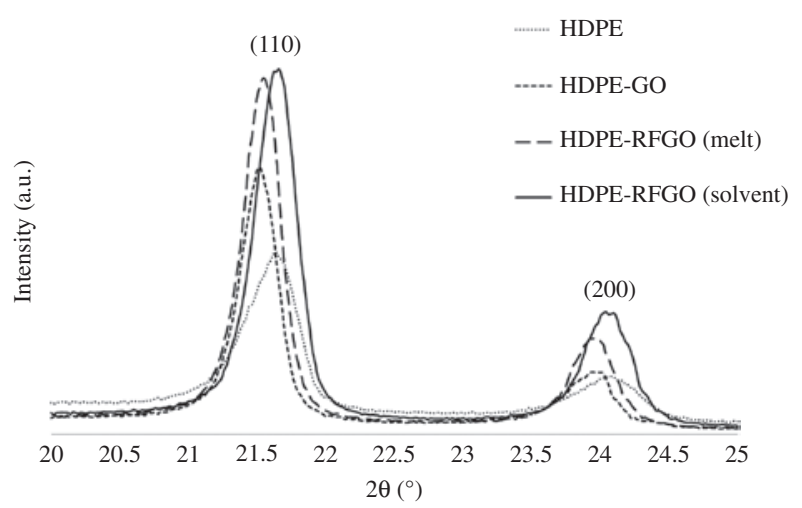

Figure 5: XRD patterns of HDPE (round dotted line), HDPE-GO (square dotted line), HDPE-RFGO Melt (dashed line) and HDPE-RFGO Solvent (solid line). when introducing the graphene-based filler to the polymer. Also, the peaks of HDPE-RFGO are higher than the ones of HDPE-GO, which is in good agreement with that found with DSC characterization. The HDPE in the composite is expected, given the XRD and DSC outcome, to have more ordered molecular chains than pure HDPE [51]. Thus, apart from increasing the crystallinity, the introduction of RFGO also optimized the local lattice order of HDPE.

The HDT values of HDPE and its composites are indicated in Table 5. The incorporation of GO in the matrix barely enhances its heat resistance ( $2 \%$ increase), whereas a more powerful increase was registered in the case of HDPE-RFGO melt ( $9 \%$ increase) and HDPE-RFGO solvent (17\% increase). This is because, upon GO modification, the reinforcing filler is fully exfoliated and homogeneously dispersed into the polymer matrix, leading to more affinity between HDPE and RFGO. The latter is thus able to transfer high thermal stability and heat resistance to the former. When comparing HDPE-RFGO (melt) with HDPERFGO (solvent), HDT in the case of solvent reaction is higher because more intimate contact between HDPE and RFGO increases the strength of their interactions, leading to an improved interfacial adhesion [52]. This agrees with the mechanical performance results.

\section{Conclusion}

Functionalization and reduction of GO was undertaken to assess the effect of this modified carbon-based reinforcing filler (RFGO) in enhancing the mechanical performance, thermal stability, and crystallization behavior of HDPE. XPS and TGA proved the nucleophilic addition method (with DA and hydrazine monohydrate) to be successful in introducing amine functionalities on the GO structure and restoring most of the $s p^{2} \mathrm{C}=\mathrm{C}$ double bonds. Tensile tests helped in evaluating the reinforcing effect of RFGO in terms of increased strength, modulus, and toughness. A significant enhancement of these properties was observed upon GO modification because this ensured a more homogeneous distribution of the reinforcing filler in the polymer matrix, strengthening the interfacial interactions and facilitating the stress transfer. However, the increase in mechanical properties for HDPE-RGO composites made via melt mixing was not as exciting as the one regarding HDPE-RFGO (solvent) because the melt blending procedure does not lead to very intimate contact between polymer and filler. The introduction of RFGO in the HDPE matrix also made it more thermally stable, with a significant boost of the degradation temperatures, regardless of the HDPE-RFGO manufacturing method 
applied because the ability of RFGO to act as a gas barrier and delay the polymer thermal degradation remained unchanged. The maximum degradation temperature of HDPE-RFGO (solvent) increased by $7.1^{\circ} \mathrm{C}$, in comparison with HDPE. DSC and XRD proved that polymer crystallinity, as well as its crystallization temperature and melting point, increased with RFGO added as a filler via solvent reaction from $63 \%$ to $72 \%$, from $118.8^{\circ} \mathrm{C}$ to $123.5^{\circ} \mathrm{C}$, and from $133.3^{\circ} \mathrm{C}$ to $134.9^{\circ} \mathrm{C}$, respectively. The introduction of RFGO to HDPE leads to heterogeneous crystallization of the polymer, facilitating nucleation and significant crystal growth, even when the HDPE-RFGO composite was created by melt mixing instead of solvent reaction as the RFGO nucleating effect in influencing the crystallization behavior of HDPE always remains efficient due to its very high aspect ratio and surface area. The HDT of the polymer was enhanced by $1.1^{\circ} \mathrm{C}$ with the introduction of $\mathrm{GO}$, by $4.3^{\circ} \mathrm{C}$ when adding RFGO (via melt mixing), and by $8^{\circ} \mathrm{C}$ with the addition of RFGO (through solvent reaction), proving that the stronger interactions between matrix and filler, brought about by the solvent reaction method, led to higher HDPE heat resistance. Even though solvent reaction offers more affinity between matrix and filler, melt compounding is more flexible, cheaper, and less harmful to the environment because no solvents or chemicals need to be used. All the property characterizations conducted in this study proved that the performance enhancements of HDPE-RFGO (made through melt mixing) are the same as the one of HDPE-RFGO (made via solvent reaction), except for mechanical properties. Optimization of the ecofriendlier approach (melt mixing) is ongoing to encourage its full consideration when manufacturing graphenebased thermoplastic nanocomposites, leading to mass production for advanced and highly demanding industrial applications.

Acknowledgments: This work was supported by the Ontario Research Fund program. Technical help from Samir Konar and Donatello Salvagno is also greatly appreciated.

Conflict of interest statement: The authors declare no conflicts of interest regarding this article.

\section{References}

[1] McDaniel MP, DesLauriers PJ. Ethylene Polymers, HDPE. In Kirk-Othmer Encyclopedia of Chemical Technology. John Wiley \& Sons, Inc.: NJ, USA, 2015.
[2] Zheng Q, Zhou JF, Song YH. J. Mater. Res. 2004, 19, 2625-2634.

[3] Wu G, Zheng Q. J. Polym. Sci. Part B. Polym. Phys. 2004, 42, 1199-1205.

[4] Yang S, Taha-Tijerina J, Serrato-Diaz V, Hernandez K, Lozano K. Compos. B Eng. 2007, 38, 228-235.

[5] Mohanty S, Verma SK, Nayak SK. Compos. Sci. Technol. 2006, 66, 538-547.

[6] Barone JR, Schmidt WF, Liebner CFE. Compos. Sci. Technol. 2005, 65, 683-692.

[7] Panthapulakkal S, Sain M. Compos. Part A Appl. Sci. Manuf. 2007, 38, 1445-1454.

[8] Aji IS, Zainudin ES, Abdan K, Sapuan SM, Khairul MD. J. Compos. Mater. 2013, 47, 979-990.

[9] Facca AG, Kortschot MT, Yan N. Compos. Sci. Technol. 2007, 67, 2454-2466.

[10] Baniasadi H, Ramazani A, Javan Nikkhah S. Mater. Des. 2010, 31, 76-84.

[11] Gopakumar TG, Lee JA, Kontopoulou M, Parent JS. Polymer (Guildf) 2002, 43, 5483-5491.

[12] Liang L, Gao C, Chen G, Guo C-Y. J. Mater. Chem. C 2016, 4, 526-532.

[13] Park OK, Jeevananda T, Kim NH, Kim S, Lee JH. Scr. Mater. 2009, 60, 551-554.

[14] Rahmat M, Hubert P. Compos. Sci. Technol. 2011, 72, 72-84.

[15] Sahoo NG, Rana S, Cho JW, Li L, Chan SH. Prog. Polym. Sci. 2010, 35, 837-867.

[16] Shin SYA, Simon LC, Soares JBP, Scholz G. Polymer (Guildf) 2003, 44, 5317-5321.

[17] Kojima Y, Usuki A, Kawasumi M, Okada A. J. Mater. Res. 1993, 8, 1179.

[18] Xu B, Zheng Q, Song Y, Shangguan Y. Polymer (Guildf) 2006, 47, 2904-2910.

[19] Liu F, Zhang X, Li W, Cheng J, Tao X, Li Y, Sheng L. Compos. Part A Appl. Sci. Manuf. 2009, 40, 1717-1721.

[20] Haggenmueller R, Fischer JE, Winey KI. Macromolecules 2006, 39, 2964-2971.

[21] Morcom M, Atkinson K, Simon GP. Polymer (Guildf) 2010, 51, 3540-3550.

[22] Kanagaraj S, Varanda FR, Zhil'tsova TV, Oliveira MSA, Simões JAO. Compos. Sci. Technol. 2007, 67, 3071-3077.

[23] Mai F, Wang K, Yao M, Deng H, Chen F, Fu Q. J. Phys. Chem. B 2010, 114, 10693-10702.

[24] Ramanathan T, Abdala AA, Stankovich S, Dikin DA, HerreraAlonso M, Piner RD, Adamson DH, Schniepp HC, Chen X, Ruoff RS, Nguyen ST, Aksay IA, Prud'Homme RK, Brinson LC. Nat. Nanotechnol. 2008, 3, 327-331.

[25] Hu H, Allan CCK, Li J, Kong Y, Wang X, Xin JH, Hu H. Nano Res. 2014, 7, 418-433.

[26] Notley SM. Langmuir 2012, 28, 14110-14113.

[27] Hernandez Y, Nicolosi V, Lotya M, Blighe FM, Sun Z, De S, McGovern IT, Holland B, Byrne M, Gun'ko YK, Boland JJ, Niraj P, Duesberg G, Krishnamurthy S, Goodhue R, Hutchison J, Scardaci V, Ferrari AC, Coleman JN. Nat. Nanotechnol. 2008, 3, 563-568.

[28] Zhu Y, Murali S, Cai W, Li X, Suk JW, Potts JR, Ruoff RS. Adv. Mater. 2010, 22, 3906-3924.

[29] Stankovich S, Dikin DA, Piner RD, Kohlhaas KA, Kleinhammes A, Jia Y, Wu Y, Nguyen SBT, Ruoff RS. Carbon N Y 2007, 45, 1558-1565. 
[30] Kim H, Abdala AA, MacOsko CW. Macromolecules 2010, 43, 6515-6530.

[31] Tripathi SN, Rao GSS, Mathur AB, Jasra R. RSC Adv. 2017, 7, 23615-23632.

[32] Potts JR, Dreyer DR, Bielawski CW, Ruoff RS. Polymer (Guildf) 2011, 52, 5-25.

[33] Dhand V, Rhee KY, Ju Kim H, Ho Jung D. J. Nanomater. 2013, 2013, 14.

[34] Ovid'ko IA. Rev. Adv. Mater. Sci. 2013, 34, 19-25.

[35] Layek RK, Nandi AK. Polym. (United Kingdom) 2013, 54, 5087-5103.

[36] Cai D, Song M. J. Mater. Chem. 2010, 20, 7906.

[37] Ren PG, Wang H, Huang HD, Yan DX, Li ZM. J. Appl. Polym. Sci. 2014, 131, 1-9.

[38] Zheng W, Lu X, Wong S-C. J. Appl. Polym. Sci. 2004, 91, 2781-2788.

[39] Cheng S, Chen X, Hsuan YG, Li CY. Macromolecules 2012, 45, 993-1000.

[40] El Achaby M, Qaiss A. Mater. Des. 2013, 44, 81-89.

[41] Yao G, Duan T, An M, Xu H, Tian F, Wang Z. RSC. Adv. 2017, 7, 21918-21925.
[42] Samal M, Mohapatra P, Subbiah R, Lee C-L, Anass B, Kim JA, Kim T, Yi DK. Nanoscale 2013, 5, 9793.

[43] Park CS, Choi KS, Shin JW, Kim SY. J. Nanosci. Nanotechnol. 2015, 15, 2060-2066.

[44] Shim SH, Kim KT, Lee JU, Jo WH. ACS Appl. Mater. Interfaces. 2012, 4, 4184-4191.

[45] Dehghanzad B, Razavi Aghjeh MK, Rafeie 0, Tavakoli A, Jameie Oskooie A. RSC Adv. 2016, 6, 3578-3585.

[46] Lei H, Liu Z, He C, Zhang S-C, Liu Y-Q, Hua C-J, Li X-M, Li F, Chen C-M, Cai R. RSC Adv. 2016, 6, 101492-101500.

[47] Liu H, Brinson LC. Compos. Sci. Technol. 2008, 68, 1502-1512.

[48] Chatterjee A, Deopura BL. J. Appl. Polym. Sci. 2006, 100, 3574-3578.

[49] Kodjie SL, Li L, Li B, Cai W, Li CY, Keating M. J. Macromol. Sci. - Phys. B 2006, 45, 231-245.

[50] Wood-Adams PM, Dealy JM, DeGroot AW, Redwine OD. Macromolecules 2000, 33, 7489-7499.

[51] Hindeleh AM, Johnson DJ. Polymer (Guildf) 1978, 19, 27-32.

[52] Sahoo S, Misra M, Mohanty AK. Compos. Part A Appl. Sci. Manuf. 2011, 42, 1710-1718. 